\title{
Genetic basis of arsenite and cadmium tolerance in Saccharomyces
} cerevisiae

\author{
Michael Thorsen ${ }^{\dagger 1,4}$, Gabriel G Perrone ${ }^{\dagger 2}$, Erik Kristiansson ${ }^{3}$, Mathew Traini2 \\ Tian $\mathrm{Ye}^{1}$, Ian W Dawes ${ }^{2}$, Olle Nerman ${ }^{3}$ and Markus J Tamás*1
}

\begin{abstract}
Address: ${ }^{1}$ Department of Cell and Molecular Biology/Microbiology, University of Gothenburg, S-405 30 Gothenburg, Sweden, ${ }^{2}$ Ramaciotti Centre for Gene Function Analysis, School of Biotechnology and Biomolecular Sciences, University of New South Wales, Sydney, NSW 2052, Australia, ${ }^{3}$ Department of Mathematical Statistics, Chalmers University of Technology/University of Gothenburg, S-412 96 Gothenburg, Sweden and ${ }^{4}$ Department of Biology, University of Copenhagen, Copenhagen, Denmark

Email: Michael Thorsen - mthorsen@bio.ku.dk; Gabriel G Perrone - g.perrone@unsw.edu.au; Erik Kristiansson - erik.kristiansson@zool.gu.se; Mathew Traini - mathew.traini@unsw.edu.au; Tian Ye - tian.ye@cmb.gu.se; Ian W Dawes - i.dawes@unsw.edu.au;

Olle Nerman -nerman@math.chalmers.se; Markus J Tamás* - markus.tamas@cmb.gu.se

* Corresponding author †Equal contributors
\end{abstract}

Published: 12 March 2009

BMC Genomics 2009, 10:105 doi:10.1/86/147|-2164-10-105
Received: 10 October 2008

Accepted: 12 March 2009

This article is available from: http://www.biomedcentral.com/I47I-2/64/I0/105

(C) 2009 Thorsen et al; licensee BioMed Central Ltd.

This is an Open Access article distributed under the terms of the Creative Commons Attribution License (http://creativecommons.org/licenses/by/2.0), which permits unrestricted use, distribution, and reproduction in any medium, provided the original work is properly cited.

\begin{abstract}
Background: Arsenic and cadmium are widely distributed in nature and pose serious threats to the environment and human health. Exposure to these nonessential toxic metals may result in a variety of human diseases including cancer. However, arsenic and cadmium toxicity targets and the cellular systems contributing to tolerance acquisition are not fully known.
\end{abstract}

Results: To gain insight into metal action and cellular tolerance mechanisms, we carried out genome-wide screening of the Saccharomyces cerevisiae haploid and homozygous diploid deletion mutant collections and scored for reduced growth in the presence of arsenite or cadmium. Processes found to be required for tolerance to both metals included sulphur and glutathione biosynthesis, environmental sensing, mRNA synthesis and transcription, and vacuolar/endosomal transport and sorting. We also identified metal-specific defence processes. Arsenite-specific defence functions were related to cell cycle regulation, lipid and fatty acid metabolism, mitochondrial biogenesis, and the cytoskeleton whereas cadmium-specific defence functions were mainly related to sugar/carbohydrate metabolism, and metal-ion homeostasis and transport. Molecular evidence indicated that the cytoskeleton is targeted by arsenite and that phosphorylation of the Snflp kinase is required for cadmium tolerance.

Conclusion: This study has pin-pointed core functions that protect cells from arsenite and cadmium toxicity. It also emphasizes the existence of both common and specific defence systems. Since many of the yeast genes that confer tolerance to these agents have homologues in humans, similar biological processes may act in yeast and humans to prevent metal toxicity and carcinogenesis. 


\section{Background}

The presence of nonessential metals like arsenic (As) and cadmium (Cd) in the environment is prevalent. Since these metals are highly toxic, they pose a considerable threat to nature and to human health. The main routes of poisoning are through occupational exposure or through ingestion of contaminated food and water. Pollution of soils with toxic agents is a common global problem, and contamination of drinking water by arsenic is a major health concern because of the large number of contaminated sites and people at risk. These metals are implicated in a broad spectrum of degenerative conditions in humans, including neurotoxicity, nephrotoxicity, genotoxicity and carcinogenesis. For example, chronic As exposure induces cardiovascular diseases, neurological disorders and liver injury, and is associated with cancers of the skin, bladder, liver and lung. Cd is considered genotoxic and carcinogenic for lung, kidney and prostate [14]. The International Agency for Research on Cancer (IARC) classifies both metals as group I carcinogens [5].

The toxicity mechanisms of As and Cd are not fully understood at the molecular level. In general, they may act by targeting signalling or regulatory proteins that control cell proliferation, differentiation and cell cycle regulation. Although the mode of action of each metal is likely to involve unique features, some toxicity mechanisms may be shared. Similarly, cells may mount both common and metal-specific responses to counteract toxicity $[2,6-8]$. A common property of As and Cd is their high reactivity with sulphhydryl groups. Hence, they can bind to and affect the activity of many proteins. In addition, these metals are known to generate oxidative stress in cells and their toxicity has partly been attributed to their capability to induce formation of reactive oxygen species (ROS). The damage caused by ROS to lipids, proteins and DNA are likely to contribute to As and Cd toxicity $[7,9]$. Nevertheless, neither the exact details of metal-induced ROS generation nor the full set of toxicity targets is known.

Drugs containing arsenicals are currently used in medical treatment. The arsenic-containing drug melarsoprol ${ }^{\varpi}$ is used to treat diseases caused by the protozoan parasite Trypanosoma $[10,11]$, whereas arsenic trioxide $\left(\right.$ Trisenox $^{\circledast}$ ) is used as a treatment for acute promyelocytic leukaemia and it may also be employed for other haematological and solid cancers [12]. However, the emergence of resistance threatens the efficacy of medical treatment [13] and hence, there is an increasing demand to identify tolerance mechanisms. Similarly, the prospect of using plants to clean up polluted soils has recently attracted considerable attention. Nevertheless, to develop phytoremediation into a useful approach requires a detailed understanding of the genetics and molecular basis of detoxification and tolerance acquisition $[14,15]$.
Tolerance and detoxification mechanisms often involve extrusion of the toxic ions from the cell, sequestration within internal organelles, chelation by metal-binding proteins, and reduction of uptake. Common to these systems is that they reduce the cellular content of the toxic agent, although their molecular basis may differ between metals and also between organisms [16-19]. Furthermore, it is clear that not only the detoxification systems themselves, but also the proteins that regulate their expression, localization and/or activity will contribute to cellular metal tolerance.

The aim of this work was to provide a global view of the genetic basis of As and Cd toxicity and detoxification by identifying the molecular/cellular targets of their action and to reveal tolerance acquisition mechanisms. Unveiling metal toxicity and tolerance mechanisms in yeast may prove of value for identifying similar mechanisms in higher eukaryotes.

\section{Results and discussion Identification of arsenite and cadmium sensitive yeast mutants}

We individually exposed $\sim 4700$ haploid Saccharomyces cerevisiae gene deletion mutants (the entire set of nonessential genes in this yeast) to arsenite and cadmium. The screen was limited to the trivalent form of arsenic (arsenite) since arsenite is more toxic than arsenate and is the form that is principally responsible for the biological effects of arsenic in medical therapy. Cells were exposed to increasing concentrations of each metal (3 doses) on solid medium and their growth was monitored by digital imaging and computational analysis as described in the Methods section. Deletion strains were considered sensitive if they showed a significant growth reduction in the presence of metal compared to its growth in the absence of metal. We also screened the homozygous diploid strain collection to ensure that phenotypes manifested only in haploid or diploid strain backgrounds were identified. In this case, homozygous deletion strains that exhibited reduced growth relative to the wild-type in liquid medium containing metal were identified as sensitive. Sensitivity of these strains was confirmed by re-screening. The combined set of deletion strains from the two screens (haploid and homozygous diploid) comprised 306 arsenite-sensitive and 382 cadmium-sensitive mutants. 106 mutants $(18 \%)$ were sensitive to both metals (Fig 1A). For a list of all As and Cd sensitive mutants, see Additional file 1.

\section{Cellular functions contributing to both arsenite and cadmium tolerance}

To pin-point cellular functions that protect cells from metal toxicity, we searched for functional categories (according to FunCat, Munich Information Center for Protein Sequences (MIPS) [20]) that were significantly 
A

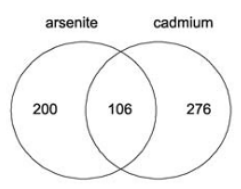

C

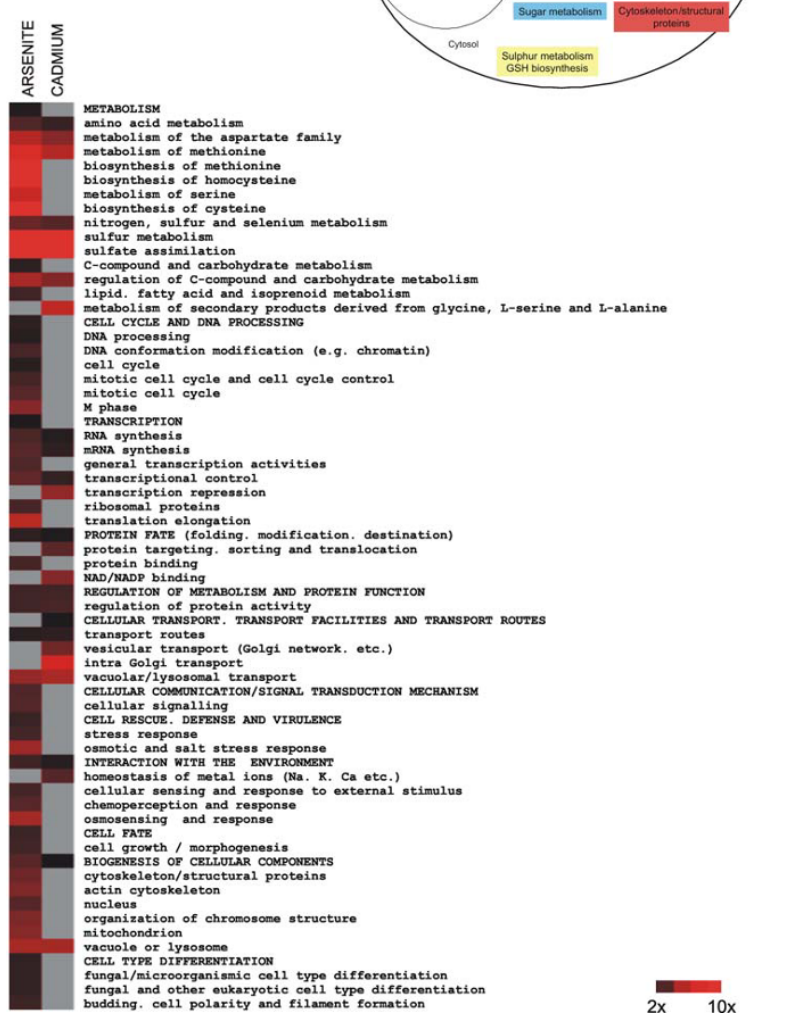

Figure I

Analysis of yeast genes conferring arsenite and cadmium tolerance. (A) Venn diagram visualizing unique and common $\mathrm{As}$ and $\mathrm{Cd}$ sensitive yeast mutants identified in this work. (B) Model showing selected functional categories (according to FunCats (MIPS)) that are affected by As and $\mathrm{Cd}$. Yellow: function required for both $\mathrm{As}$ and $\mathrm{Cd}$ tolerance; Red: function required for As tolerance; Blue: function required for $\mathrm{Cd}$ tolerance. (C) Heat map depicting all functional categories in our data set that were significantly ( $p$ value $<0.005)$ enriched for $A s$ and $C d$ sensitive mutants. Parent terms are in capitals, child terms in lower case letters. The colour indicates the fold enrichment of genes within individual categories. Gray boxes indicate a category that did not pass the significance ( $p$-value $<0.005$ ) cut-off.

enriched ( $p$-value $<0.005)$ in the sensitive gene set as compared to the whole genome. As was the case with individual genes (see above), this analysis revealed common as well as metal-specific tolerance functions (Fig 1). Prominent among those required for both As and Cd tolerance, were functions related to methionine and sulphur metabolism, mRNA synthesis and transcriptional regulation, environmental sensing, and vacuolar/endosomal trans- port and sorting. The $p$-values and fold enrichment factors of genes within individual functional categories are available in Fig 1C and Additional file 1.

\section{Methionine and sulphur metabolism}

Cells respond to As or Cd exposure by inducing expression of genes and enzymes in the sulphur assimilation and glutathione biosynthesis pathways. Moreover, cells also channel a large part of assimilated sulphur into biosynthesis of the low molecular weight thiol molecule glutathione [21-24]. Glutathione is important for metal tolerance since it may protect cells by: 1) metal chelation and sequestration; 2) protection against metal-induced oxidation since glutathione is considered the main redox buffer of the cell; and 3) binding to reactive sulphhydryl groups on proteins (glutathionylation) to shield them from irreversible metal binding and/or oxidative damage $[25,26]$. The fact that we identified several metal sensitive mutants having functions in the sulphur assimilation and glutathione biosynthesis pathways as well as transcriptional regulators controlling these pathways, underscores the importance of the sulphur/glutathione biosynthesis pathways for tolerance acquisition. Moreover, the $\gamma c f 1 \Delta$ mutant lacking an ABC-type transporter responsible for sequestration of metal-glutathione conjugates into vacuoles [27-29] was also As and Cd sensitive. The enzymes in the sulphur assimilation/glutathione biosynthesis pathways are transcriptionally regulated by the transcription factors Yap1p and Met4p, and cells lacking any of these factors display As and Cd sensitivity $[21,22]$. Met $4 p$ is recruited to target promoters by the DNA-binding proteins Met31p, Met32p and Cbf1p forming the complexes Met4p-Met31p/Met32p and Met4p-Cbf1p. An additional protein, Met28p stabilizes the Met4p-containing complexes [30]. Our data confirms the importance of Yap1p for metal tolerance and suggests that different Met4pcomplexes may be important during As and Cd exposure; mutants lacking MET28 and CBF1 were As-sensitive whereas cells lacking MET32 and MET28 were Cd-sensitive. Taken together, these findings are consistent with the central role of sulphur metabolism and glutathione biosynthesis for As and Cd tolerance.

\section{$m R N A$ synthesis and transcriptional regulation}

As or Cd exposure results in altered expression of a large number of genes [21,22,31-33]. Accordingly, mutants defective in mRNA synthesis and transcriptional control were sensitized to both metals (Fig 1). Among the genespecific regulators that confer metal tolerance was Yap1p (regulates expression of genes with functions in oxidative stress defence and sulphur/glutathione metabolism), Met28p, Cbf1p, Met32p (sulphur/glutathione metabolism) and Rpn4p (protein degradation). Transcriptional activators may stimulate gene-specific expression by recruiting the co-regulator complexes Mediator, SAGA 
and/or Swi/Snf as well as RNA polymerase II to promoters. Indeed, several metal-sensitive mutants lacked subunits of RNA polymerase II $(r p b 4 \Delta, r p b 9 \Delta)$ or components of the Mediator $(p g d 1 \Delta, \operatorname{srb} 8)$, SAGA $(g c n 5 \Delta, a d a 2 \Delta$, $s p t 7 \Delta)$, and Swi/Snf (swi3 $\Delta, \operatorname{snf} 2 \Delta$ ) co-regulator complexes. Although sensitivity of these mutants could be a result of a general impairment of transcriptional activity, both Yap1p and Met4p interact physically with components of these co-regulator complexes [34,35].

\section{Interaction with the environment}

Cells defective in functions related to environmental sensing and signalling were metal sensitive (Fig 1). The limited overlap between the As and Cd sensitive mutants within this category suggests that cells may use distinct sensing/ signalling pathways in response to these metals. For instance, cells appear to use distinct MAP kinase pathways for sensing/responding to As and Cd since mutants defective in the cell integrity pathway $(\operatorname{slg} 1 \Delta, b \operatorname{ck} 1 \Delta, \operatorname{sit} 2 \Delta)$ were preferentially Cd sensitive whereas cells defective in the osmosensing HOG pathway $(s s k 1 \Delta, s s k 2 \Delta, p b s 2 \Delta, h o g 1 \Delta)$ were preferentially As sensitive. We note that cells lacking the HOG pathway components Ssk1p and Hog1p were also Cd sensitive. The As and Cd-sensitivity of the latter mutants may reflect different functions/targets of the corresponding proteins under the two stress conditions. Hog1p is phosphorylated in response to As and contributes to tolerance by at least two mechanisms; first, Hog1p restricts arsenite influx through the aquaglyceroporin Fps1p by phosphorylating this protein (deletion of FPS1 results in arsenite resistance) [36,37]. Secondly, Hog1p regulates the exit from As-induced $G_{1}$ arrest [38]. Hog1p is also phosphorylated in response to Cd [39] but the target(s) and mechanism(s) through which Hog1p mediates Cd tolerance are unknown. Interestingly, Hog1p has a role in the cell integrity pathway and the cellular response to cell wall damage involves both the Hog1p and Slt2p/ cell integrity MAP kinase pathways [40]. The fact that cells lacking HOG1 or components of the cell integrity pathway are Cd sensitive, suggests that the role of Hog1p under Cd exposure may be linked to cell wall damage.

\section{Vacuolarlendosomal transport and sorting}

Many functions throughout the secretory pathway appear important for metal tolerance since cells defective in vacuolar acidification, endocytosis, exocytosis, vesicular transport, and vacuolar transport displayed enhanced As and Cd sensitivity (Fig 1). The fact that this category was more enriched in the Cd-sensitive gene set indicates that the secretory pathway is more severely affected by Cd than by As. Interestingly, mutants that lack individual components of various protein complexes functioning in protein sorting were metal sensitive; such mutants included components of the HOPS (homotypic fusion and vacuole protein sorting) complex (Vps16p, Vps33p), ESCRT (endosomal sorting complex required for transport) I (Stp22p, Srn2p), ESCRT II (Snf8p, Vps36p, Vps25p), ESCRT III (Snf7p, Vps20p) and GARP (Golgi-associated retrograde protein) complex (Vps51p-52p-53p-54p) (Fig 2A).

The secretory pathway is implicated in many important processes such as lipid biosynthesis, protein targeting and secretion, as well as the unfolded protein response. Consequently, an intact secretory pathway is crucial for the cell to withstand many different environmental conditions. Indeed, mutations impairing proper functioning of the secretory pathway cause sensitivity to a broad range of treatments and growth conditions [41,42]. Metals may impact one or more aspects of the secretory pathway; first, metals may enter the endomembrane system and disturb various processes by interacting with proteins and/or lipids. Secondly, failure to maintain appropriate secretory pathway function may cause metal sensitivity due to defects in delivery or targeting of transmembrane transporters, sensors or signalling receptors. Thirdly, since vac-

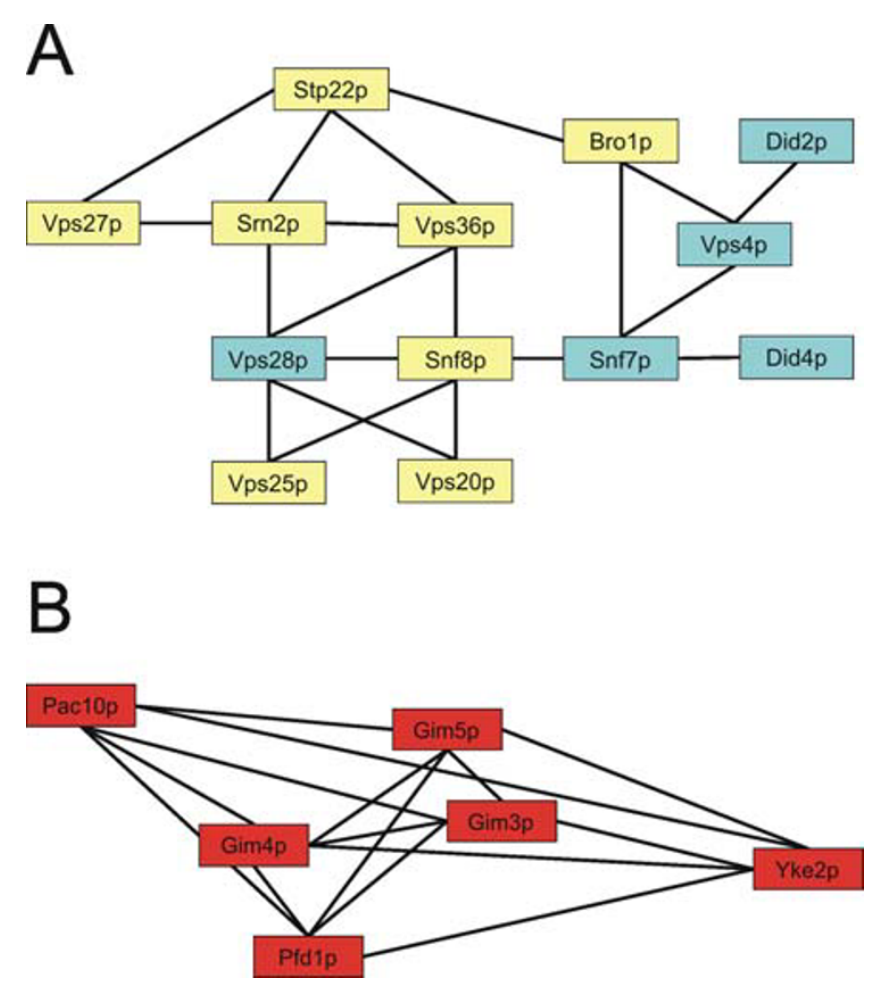

Figure 2

Example of protein complexes affected by arsenite and cadmium. (A) The ESCRT complex and (B) the GIM complex. Proteins of these complexes that confer tolerance to both metals are labelled in yellow, those that confer $\mathrm{Cd}$ tolerance are labelled in blue, and those that confer As tolerance are labelled in red. The lines indicate physical interactions between the components of the complex. 
uolar sequestration is important for tolerance acquisition, a decreased capacity to do so is likely to contribute to the observed sensitivity of secretory pathway mutants.

\section{Arsenite-specific defence functions}

Arsenite-specific defence functions that were significantly enriched ( $p$-value $<0.005$ ) in our data set were related to cell cycle regulation, lipid and fatty acid metabolism, mitochondrial biogenesis, and the cytoskeleton. The $p$ values and fold enrichment factors are available in Fig 1C and Additional file 1.

\section{Cell cycle}

Deletion of genes encoding cell cycle related functions produced As-sensitivity; those genes encompassed functions involved in regulation of cell cycle progression (HOG1, PHO85, PIN4, DBF2, CLB2), as well as spindle body and microtubule formation (BIK1, BIM1, CNM67, JNM1, CIN8, CIK1, CSM1, BNI1, CIN1, CIN2, PAC2, TUB3, SPC72). This indicates that cell cycle progression may be targeted by As, confirming our recent finding that As exposure triggers transient $G_{1}$ and $G_{2}$ delays in yeast and that cells defective in $\operatorname{Hog} 1 \mathrm{p}$ signalling cannot exit the arsenite-induced $G_{1}$ checkpoint arrest [38]. Similarly, the mechanisms of As action in cancer cells include cell cycle arrest at $G_{1}$ and $G_{2}$ phases, mitotic arrest and subsequent apoptosis. Arsenite can interrupt mitosis by interfering with tubulin polymerization or by disrupting mitotic spindles $[12,43]$. Elucidating the molecular details of arsenite-induced cell cycle regulation and how this relates to As toxicity and carcinogenicity is important for understanding the potential of As-containing drugs in medical therapy.

\section{Mitochondrion}

Many mitochondrial proteins are known to be targeted by arsenicals [44]. Indeed, we found several As-sensitive mutants defective in mitochondrial function and biogenesis, including mitochondrial protein biosynthesis and genome maintenance. This observation is consistent with the notion that arsenic toxicity targets mitochondrial processes and that impaired oxidative phosphorylation causes As sensitivity $[12,45,46]$.

\section{Lipid and fatty acid metabolism}

Deletion of genes encoding functions in lipid and fatty acid metabolism impaired As tolerance; these genes were related to ergosterol (ERG24,ERG2, ERG3,ERG4,ERG6), phospholipid (OPI1, OPI3, ARV1) and sphingolipid (DPL1, CSG2, SUR4, DEP1) biosynthesis. Trace elements and arsenicals appear to affect the fluidity and the thermotropic properties of cell membranes $[47,48]$. Hence, As may have a direct impact on the lipid bilayer. Alternatively, the lipid composition of cell membranes might be altered in the mutants listed above, thereby changing the properties of the membrane and impacting on the activities of membrane-embedded transporters, sensors or signalling receptors [49]. Interestingly, the activity of the aquaglyceroporin Fps1p, through which arsenite enters cells $[36,37]$ is affected by the plasma membrane ergosterol content [50]. Moreover, an $f p s 1 \Delta$ mutant has reduced whole-cell and plasma membrane ergosterol levels compared to wild-type cells [50]. Hence, altered plasma membrane ergosterol levels may change Fps1p activity to facilitate arsenite entry.

\section{Cytoskeleton}

Loss of genes encoding cytoskeletal proteins caused As sensitivity. In particular, mutations affecting the function of the heterohexameric GIM (Genes Involved in Microtuble biogenesis)/prefoldin protein complex, which is required for formation of functional tubulin, sensitized cells to As. These genes include YKE2 (GIM1), PAC10 (GIM2), GIM3, GIM4, GIM5, and PFD1 (GIM6). Analysis of the entire set of As-sensitive mutants for known protein-protein interactions indicated that the proteins encoded by these genes form a highly interacted molecular machine in cells and that disruption of any one of the components of this complex rendered cells sensitive to As (Fig 2B). The cytoskeleton is a known target of As; As triggers actin reorganization in various mammalian cell lines $[51,52]$, and directly interacts with actin as well as with the $\alpha$ and $\beta$ subunits of tubulin $[53,54]$.

\section{Other functions promoting arsenite tolerance}

Several other As-specific defence functions were pinpointed by our analysis (see Additional File 1). Most notable among those is the arsenic resistance gene cluster ACR3-ACR2-YAP8 [55]. ACR3 (also called ARR3) encodes an arsenite export protein [56], ACR2 (ARR2) an arsenate reductase [57] and YAP8 (ACR1/ARR1) encodes an arsenic-responsive transcription factor that controls expression of the former two genes [58-60].

\section{Cadmium-specific defence functions}

Cadmium-specific defence functions that were significantly enriched ( $p$-value $<0.005$ ) in our data set were mainly related to sugar/carbohydrate metabolism, and metal-ion homeostasis and transport. The $p$-values and fold enrichment factors are available in Fig 1C and Additional file 1.

\section{Ion homeostasis and transport}

Genes encoding functions in metal-ion homeostasis were enriched in the Cd-specific data set including the ion transporter genes PCA1 (Cd exporting ATPase), TRK1 ( $\mathrm{K}^{+}$ transporter) and SPF1 (ER-localized $\mathrm{Ca}^{2+}$ ATPase). Interestingly, the majority of the genes in this category encode functions related to iron homeostasis including the iron regulated transcription factors AFT2 and AFT1/RCS1, the 
multicopper oxidases FET3 and FET5 (involved in iron uptake), FREG (ferric reductase), FRE8 (iron/copper reductase) and ISA2 (required for maturation of mitochondrial and cytosolic Fe-S proteins). Importantly, while this paper was being written, Ottonello and co-workers reported that iron addition rescues Cd-sensitivity of certain yeast mutants indicating that $\mathrm{Cd}$ interferes with iron homeostasis [61]. This is similar to the situation in plants where Cd exposure was shown to provoke iron deficiency [62]. Indeed, expression of several genes related to iron and heme metabolism (e.g. FET3, ATX1, FRE5, ARN1) is stimulated by $\mathrm{Cd}[22,32]$ and during iron deprivation $[63,64]$ providing further support to the notion that $\mathrm{Cd}-$ exposed cells experience iron deficiency. Since Fe-S cluster homeostasis regulates transcription of the iron homeostasis systems [65], our data indicate that Cd may affect one or more aspects relating to Fe-S clusters, such as their biosynthesis and/or maturation.

\section{Sugar/carbohydrate metabolism}

Another Cd-specific defence function appears to involve the glucose sensing Snf1p-pathway since cells lacking SNF1 (homologous to mammalian AMP-activated protein kinases), SNF4, REG1, SIP5 (regulators of Snf1p), and MIG2 (transcriptional repressor targeted by Snf1p) were Cd sensitive (see Additional file 1). Snf1p plays a central role in modulating carbon metabolism under glucose limiting and environmental stress conditions. Snf1p also regulates proteins involved in metabolism of reserve carbohydrates such as glycogen and trehalose [66]. Interestingly, we noted that cells lacking either phosphofructokinase (PFK1 or PFK2) were Cd sensitive. Moreover, deletion of $F B P 1$, whose product acts in the reverse step from that catalysed by Pfk1p and Pfk $2 \mathrm{p}$ also led to Cd sensitivity. Finally, Cd stimulated expression of many genes with functions in glucose metabolism (GLK1, PDC6, ALD4, VID22, FBP1, FBP26) [32]. Hence, appropriate functioning of glycolysis may be crucial for Cd tolerance. Cd could impact the cell in such a way that flux through the glycolytic pathway is altered. For example, Cd could have a direct effect on glucose uptake systems [67], on glycolysis itself or on other systems that result in an extra demand on the glycolytic pathway.

\section{Metal stress tolerance vs. oxidative stress tolerance}

The toxicity of As and Cd has in part been attributed to their potential to induce ROS formation and hence to cause oxidative damage in cells $[9,68,69]$. To address to what extent As, Cd and various oxidants have overlapping toxicity profiles, we compared our gene sets with a set of genes previously reported to mediate tolerance to a number of ROS-generating agents including hydrogen peroxide, menadione, cumene hydroperoxide, diamide, and linoleic acid 13-hydroperoxide [70]. Hierarchical cluster analysis indicated that the genes that confer toler- ance to As, $\mathrm{Cd}$ and the oxidative stress agents above are to a large extent distinct (Fig 3). Nevertheless, there was a cluster of genes whose absence resulted in sensitivity to metals and oxidative stress. The genes in the metal and oxidative stress cluster were significantly ( $p$-value $<0.005$ ) enriched in functions related to mRNA synthesis and transcriptional control, protein synthesis, ribosomal proteins and biogenesis, protein sorting and vacuolar transport, and lipid and fatty acid metabolism. Taken together, some of the genes and cellular functions required for As and Cd tolerance are also necessary for oxidative stress tolerance. However, from the sensitivity profiles it is not possible to draw any conclusions about the source and type of ROS that As and Cd generate and that in turn contribute to their toxicity. Instead, the data indicates that cells employ largely distinct protective mechanisms in different environmental conditions.

\section{Expression vs. tolerance}

In agreement with other studies [71], we found little overlap between genes necessary for As or Cd tolerance and genes whose expression is induced by As or Cd. However, for some defence systems there appears to be such a correlation. For instance, most genes (and enzymes) of the sulphur assimilation and glutathione biosynthesis pathways were strongly up-regulated in response to As and $\mathrm{Cd}$ $[21,22,32]$, and many mutants in this pathway were metal sensitive. Another example is genes involved in iron homeostasis: expression of several such genes was induced by Cd whereas their absence resulted in Cd sensitivity. Similarly, expression of the arsenic-resistance genes ACR2 and ACR3 was stimulated by As and their presence was required for As tolerance (see Additional file 1).

We next asked whether the gene expression profiles of Asand Cd-treated cells would be more similar to each other than the As and Cd sensitivity profiles. As stimulated expression of 334 genes ( $0.2 \mathrm{mM}$ arsenite, 1 hour) [21] whereas Cd exposure increased expression of 305 genes ( $0.3 \mathrm{mM} \mathrm{Cd}, 2$ hours) [32] of which 80 genes were common (see Additional file 1). The overlap in those gene sets was about $14 \%$ which is similar to the overlap in the sensitive gene sets (18\%). Interestingly, the genes induced by both treatments mainly encode functions in sulphur assimilation and glutathione biosynthesis pathways as well as in (oxidative) stress responses and detoxification, and many are transcriptionally regulated by Met $4 p$ and Yap1p. Hence, several processes that contribute to both As and Cd tolerance are transcriptionally stimulated by these metals. We also checked the overlap between the common As/Cd sensitivity gene set (106 genes) and the common As/Cd-induced gene set ( 80 genes). Curiously, these gene sets only had three genes in common (MET16, MET17, CYS3). Hence, although the two gene sets (phenotype and expression) are enriched for genes encoding 


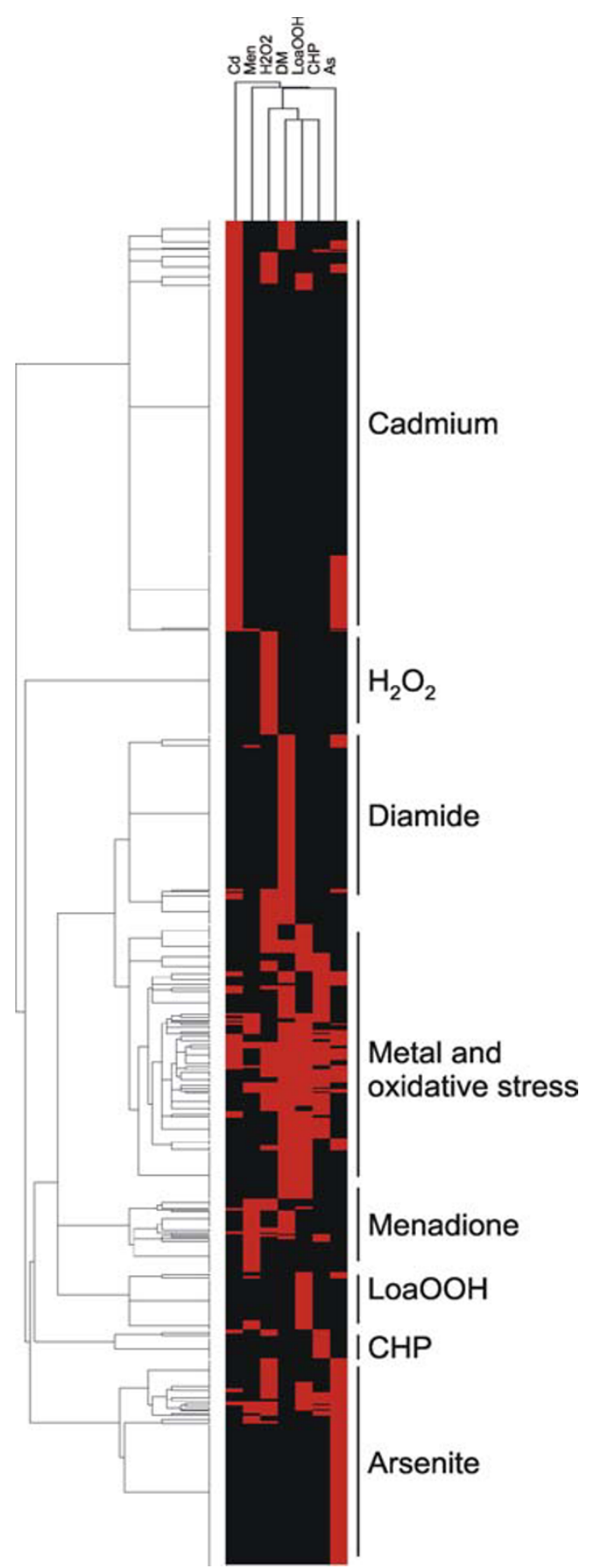

Figure 3

Genes conferring tolerance to arsenite, cadmium and oxidative stress generating agents. Hierarchical cluster analysis of mutants that are sensitive to metals or oxidative stress generating agents. Abbreviations used in the heat-map: As (arsenite), $\mathrm{Cd}$ (cadmium), $\mathrm{H}_{2} \mathrm{O}_{2}$ (hydrogen peroxide), Men (menadione), CHP (cumene hydroperoxide), DM (diamide), and LoaOOH (linoleic acid I3-hydroperoxide). related functions, the identities of those genes are largely distinct.

\section{Human orthologues of yeast genes mediating arsenite and cadmium tolerance}

We next asked to what extent the genes in our As- and Cdsensitive gene set have human homologues. Using the HomoloGene database [72] we found that 43 of the 106 genes in the common As/Cd sensitive gene set have at least one human homologue $(41 \%)$ (see Additional file $1)$. These proteins are involved in diverse functions in humans including signalling, transcription, chromatin modification, and vacuolar protein sorting. Moreover, these genes were significantly ( $p$-value $<0.005)$ enriched for functions related to carbohydrate metabolism as well as protein targeting and sorting. We conclude that similar biological processes may act in yeast and humans to prevent metal toxicity and carcinogenesis.

\section{Comparison of this study to other genome-wide screens}

While preparing this manuscript, several genome-wide phenotypic screens were published that included arsenite and cadmium sensitivity data $[31,33,61,73,74]$. Haugen and co-workers [31] found 214 As-sensitive mutants of which $53(11 \%)$ were present also in our data set, whilst Jin et al [33] identified 65 As-sensitive mutants, 40 (12\%) of which were common to our study. 303 Cd-sensitive mutants were found by Ruotolo and colleagues [61], 73 by Serero and co-workers [74], and 276 by Jin et al [33]. Of those, $106(18 \%), 39(9 \%)$ and $94(17 \%)$ respectively were present in our gene set whereas the overlap between the Ruotolo and Serero gene sets was $19 \%$. Hence, the overlap in terms of mutants is roughly $10-20 \%$ and this relatively poor overlap is clearly visible in the heat maps in Figures 4 and 5. A reason for this discrepancy could be that none of the screens is saturated. Moreover, the corresponding screens were performed in dissimilar conditions e.g. on solid vs. liquid medium or screening mutants individually vs. in a mixture using a TAG array approach. Another factor likely to affect the outcome of a screen is the way sensitive genes are identified e.g. by visual inspection, TAG array hybridization, continuous measurements of optical density or by scoring growth after a specific time has elapsed. These factors probably influence the number and identity of mutants that are scored to affect growth. Despite the discrepancy, we reasoned that the gene sets probably contain relevant biological information. We therefore looked for mutants that were consistently identified as sensitive in at least two of the studies; these coresets contained 89 As-sensitive and 209 Cd-sensitive mutants (see Additional file 1). The As core-set was enriched in functions related to sulphur metabolism, environmental sensing and signalling, transcription, and the cytoskeleton whereas the Cd core-set was enriched in functions related to sulphur and glutathione biosynthesis, 


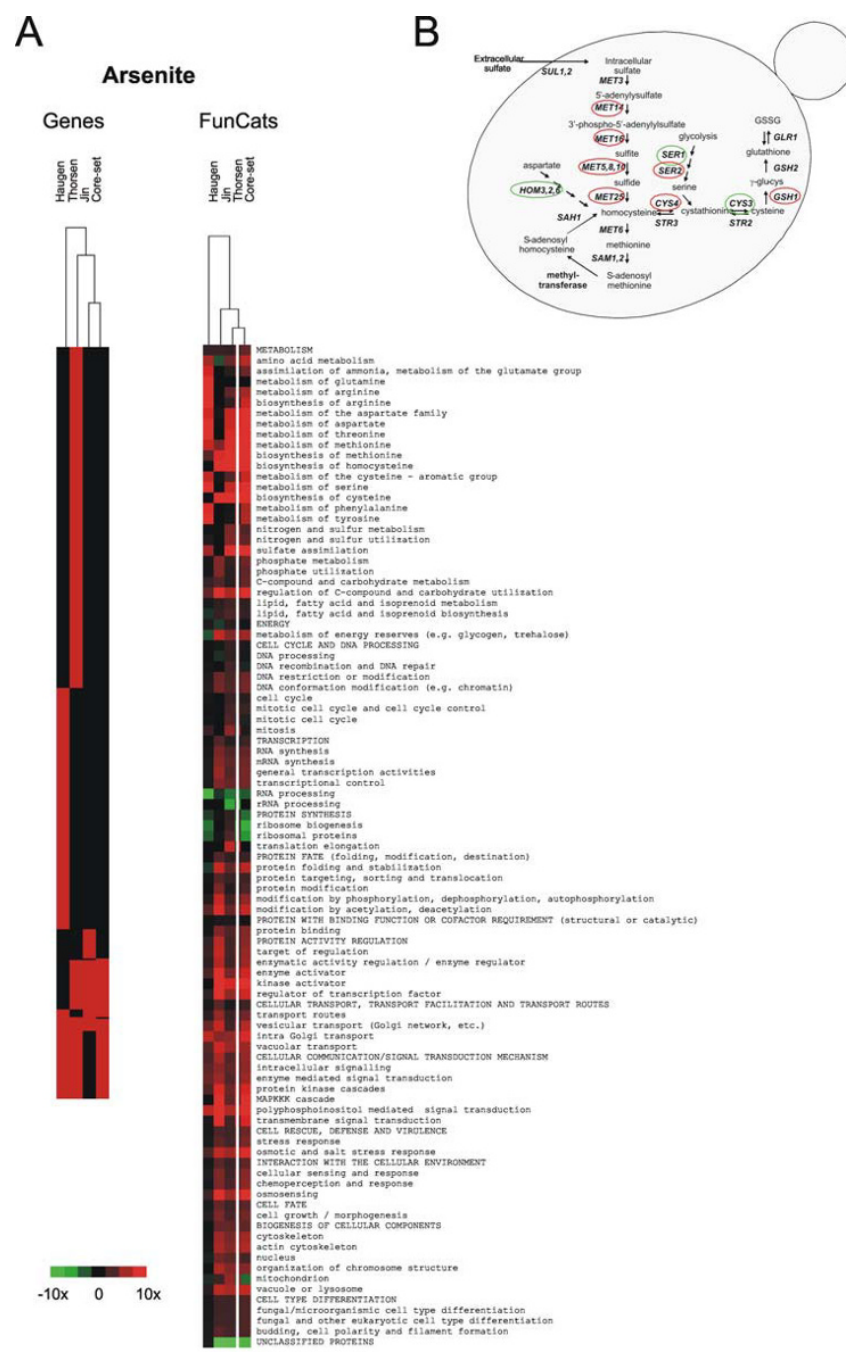

\section{Figure 4}

Comparative analysis of arsenite sensitivity data. (A) Comparison and visualization of arsenite sensitivity data from this work and other studies [3I,33]. Hierarchical cluster analysis of mutants that were scored as As sensitive and of the functional categories (according to FunCats (MIPS)) in the corresponding data sets that were significantly $(p$-value $<$ 0.005 ) enriched for As sensitive mutants in at least one of the studies. Parent terms are in capitals, child terms in lower case letters. The colour indicates the fold enrichment of genes within individual categories. (B) Arsenite sensitive mutants in the sulphur assimilation and glutathione biosynthesis pathways identified by individual screens (this work and [3I,33]). Red circles: identified by one screen only; green circles: identified by at least two studies.

transcription, intracellular transport and sorting, regulation of carbon metabolism, and metal-ion homeostasis and transport (Figs 4 and 5). Overall, these categories were similar to those found by us and others (Fig 1; $[31,33,61,74])$. As-defence genes identified in all studies

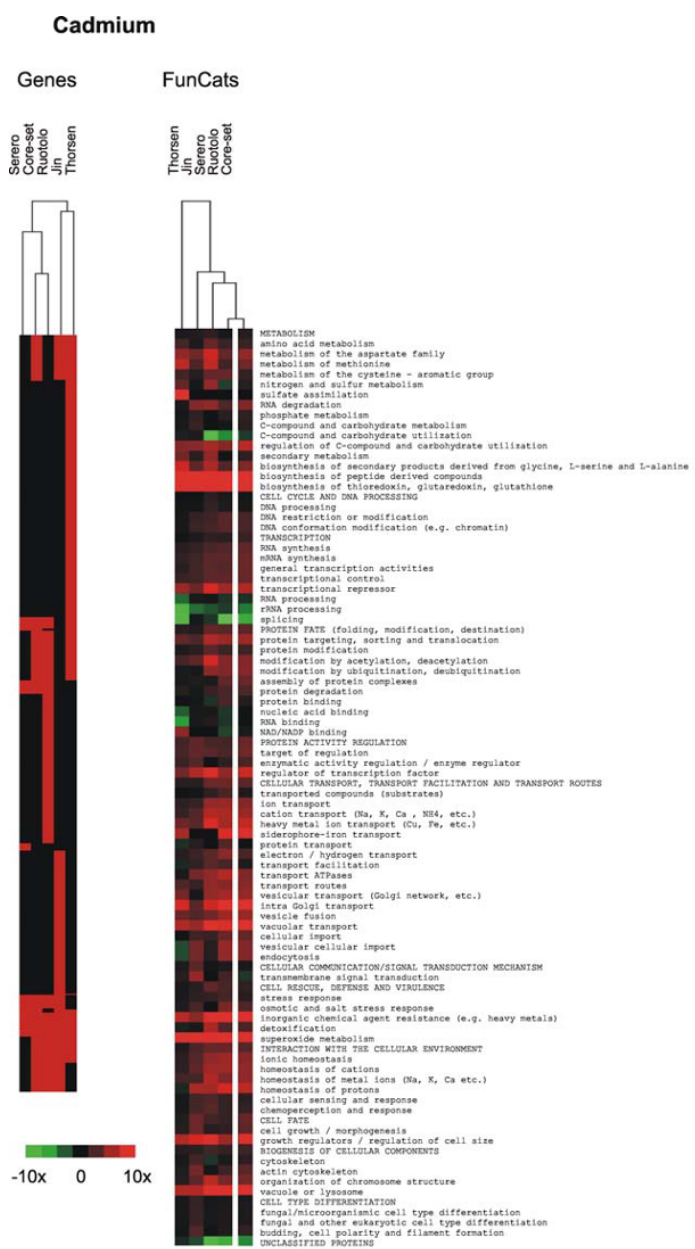

Figure 5

Comparative analysis of cadmium sensitivity data. Comparison and visualization of cadmium sensitivity data from this work and other studies $[33,61,74]$. Hierarchical cluster analysis of mutants that were scored as $\mathrm{Cd}$ sensitive and of the functional categories (according to FunCats (MIPS)) in the corresponding data sets that were significantly ( $p$-value $<0.005)$ enriched for $C d$ sensitive mutants in at least one of the studies. Parent terms are in capitals, child terms in lower case letters. The colour indicates the fold enrichment of genes within individual categories.

included YAP8, ACR3 and YCF1 whilst Cd-defence genes found in all studies included GSH1, GSH2, YCF1, YAP1 (glutathione biosynthesis), BCK1, SLT2 (MAP kinase signalling), as well as genes related to transcription and intracellular transport. Importantly, hierarchical cluster analysis of functional categories that were significantly ( $p$ value $<0.005$ ) enriched for metal sensitive mutants revealed a much better correlation than on the gene level (Figs 4 and 5). Hence, although these screens identified largely non-overlapping gene sets, they did uncover similar biological functions. In several cases, the studies above identified different mutants encoding proteins in the 
same pathway. One such example is the sulphur assimilation and glutathione biosynthesis pathways in the As-sensitive gene sets; 5 genes were common to at least two of the screens whereas 9 were found by only one study (Fig 4B). Of those, 14 were identified by us, four by Haugen and coworkers [31] and one by Jin et al [33]. Similarly, all six components of the GIM complex were found by us, four by Jin et al [33] and none by Haugen and co-workers [31]. Taken together, since the functional categories affected by metals found in each study clustered well, we conclude that genome-wide phenotypic screens provide biologically relevant insight into cellular systems mediating tolerance. However, a single screen is unlikely to uncover all genes and systems conferring tolerance.

\section{Molecular clues to arsenite and cadmium toxicity and tolerance mechanisms}

Next, we wanted to exploit the information in our data sets to discover toxicity and tolerance mechanisms at a molecular level. To do so, we explored the role of two cellular systems identified above in more detail, one related to arsenite and one related to cadmium.

\section{The cytoskeleton is targeted by arsenite}

Loss of any component of the heterohexameric GIM/prefoldin complex sensitized cells to As. The GIM complex is involved in actin and tubulin folding, and GIM mutants are defective in actin and tubulin organization, and are cold- and osmosensitive [75-77]. Interestingly, whereas GIM mutants are sensitive only at relatively high osmolarity, they are sensitive already at very low As concentrations; these mutants grew poorly at $50 \mu \mathrm{M}$ arsenite as evident from the small colonies formed (Fig 6A). To gain further insight into the role of the GIM complex, we analysed all synthetic lethal (SL) interactions between GIM genes and the genome (see Additional file 1). Of the 107 genes showing SL interactions with at least four of the GIM genes, 29 were also As-sensitive (Fig 6B) indicating a significant enrichment (Fischer's test: $9.25 \mathrm{E}^{-10}$ ) in As-sensitivity among GIM-interacting genes. These 29 genes encoded cytoskeletal proteins and functions that involve the cytoskeleton such as the cell cycle, budding and cell polarity. This data can be interpreted in two ways; As might target the GIM complex directly and that is the reason why the GIM mutants are sensitive. Alternatively, As might target the SL interacting gene-products and the cells cannot cope with defects in the GIM complex at the same time. Given that most of the interacting genes perform functions that require a functional GIM complex argues that the complex itself is directly targeted by As.

To further explore how As affects the cytoskeleton, we monitored $\alpha$-tubulin organization by following GFPtagged Tub1p and Tub3p. In the absence of As, extended fluorescence arrays were visible in most cells. In contrast,
A

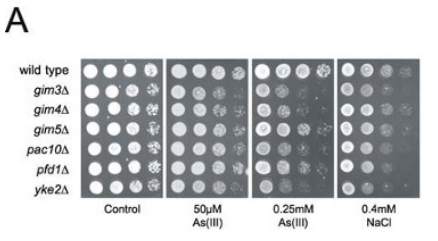

B
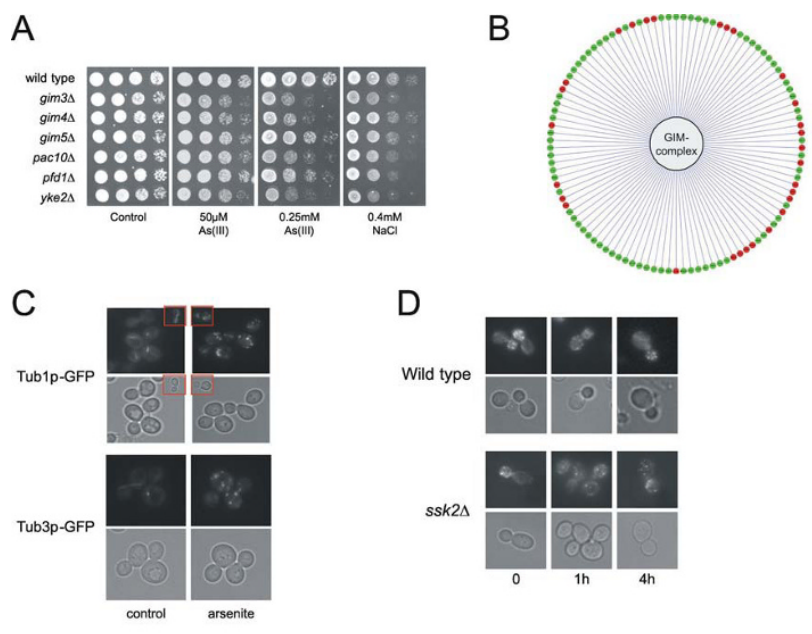

D
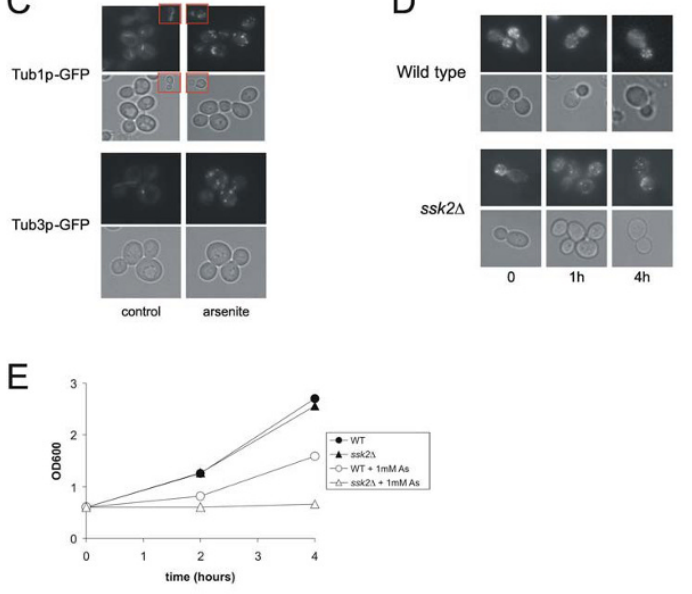

Figure 6

Arsenite targets the cytoskeleton. (A) The GIM mutants are strongly arsenite sensitive. 10-fold serial dilutions of exponentially growing cells were spotted on YEPD agar plates with arsenite or $\mathrm{NaCl}$. Growth was scored after 2-3 days at $30^{\circ} \mathrm{C}$. (B) Synthetic lethal (SL) interactions of the GIM complex. Those genes that show SL interactions with at least four of the GIM genes are shown and the red colour indicates arsenite sensitivity. (C) Morphology of the microtubule cytoskeleton. Chromosomally encoded Tublp-GFP and Tub3p-GFP were visualized in living cells before (control) and I hour after exposure to I $\mathrm{mM}$ arsenite. (D) Morphology of the actin cytoskeleton. Actin was stained with rhodaminephalloidin in wild-type and ssk $2 \Delta$ cells before and after exposure to I $\mathrm{mM}$ arsenite. (E) Growth of wild-type and ssk2 $\Delta$ cells in the presence of I $\mathrm{mM}$ arsenite.

the microtubule arrays decreased dramatically in response to As exposure indicating disassembly of cytoplasmic microtubules (Fig 6C). Also the actin cytoskeleton was strongly affected by As. In untreated wild-type cells, actin patches were predominantly localized to the buds whereas As exposure triggered a temporary depolarization of the actin cytoskeleton with an even distribution of patches in the bud and the mother cell (Fig 6D). After 4 hours, the actin cytoskeleton recovered its polar distribution in nearly all cells and this recovery coincided with growth resumption (Fig 6E). Ssk2p is a kinase that activates the MAP kinase Hog1p in response to osmotic stress. In addition, Ssk2p binds to actin and promotes actin cytoskeleton recovery after osmotic stress [78]. We previously demonstrated that $s s k 2 \Delta$ cells are As sensitive and that this sensitivity is unrelated to Hog1p phosphoryla- 
tion [36]. Instead, Ssk2p might have a role in actin recovery also during As-exposure; actin remained depolarized in As(III)-treated ssk2 $\Delta$ cells (Fig 6D) and the mutant could not resume growth (Fig 6E). Taken together, these results provide strong support for the cytoskeleton being a direct target of As toxicity and that As inhibits the activity of the GIM complex in vivo. Hence, arsenite has a dual effect on the cytoskeleton; it binds to and disrupts the actin and tubulin cytoskeleton, and it inhibits the GIM complex that is required for folding of de novo synthesised actin and tubulin monomers.

\section{Snflp phosphorylation is required for $C d$ tolerance}

The phenotypic data from our screen indicated a role of the glucose sensing Snf1p pathway for Cd tolerance. The Snf1p kinase is a heterotrimeric complex consisting of the catalytic $\alpha$-subunit Snf1p, the regulatory $\gamma$-subunit Snf4p, and one of the three $\beta$-subunits (Sip1p, Sip2p, Gal83p). Snf1p activation involves Snf4p and any of the redundant upstream kinases Sak1p, Tos3p and Elm1p that phospho-
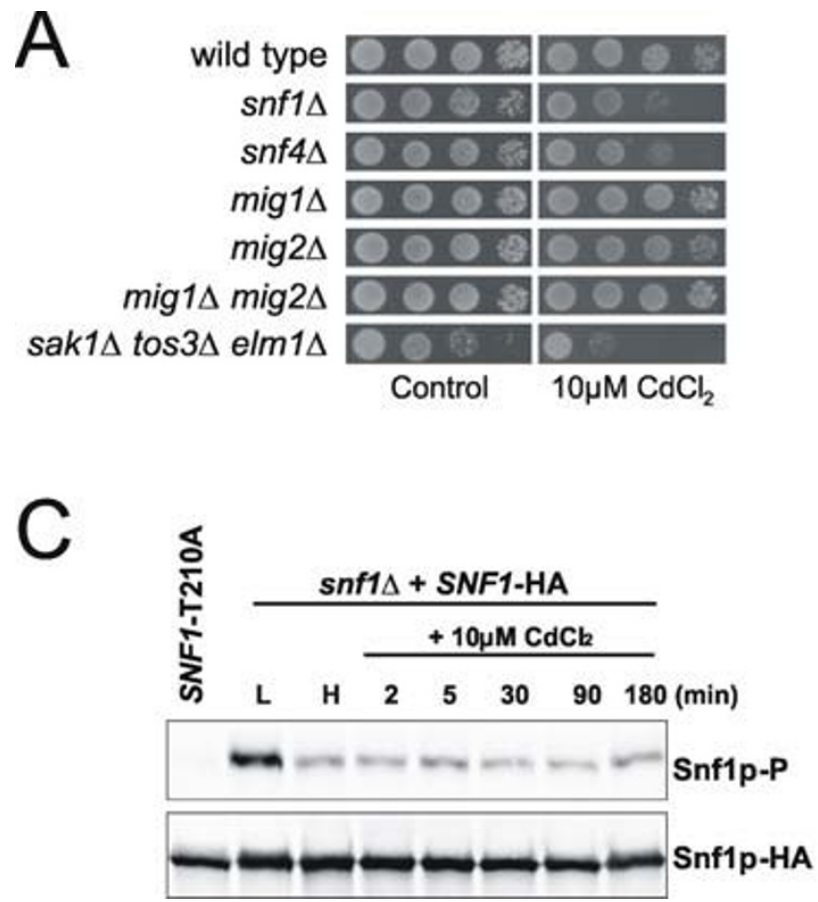

rylate Snf1p on threonine 210 (T210) [66]. We found that $s n f 1 \Delta, s n f 4 \Delta$ and the $s a k 1 \Delta$ tos $3 \Delta$ elm $1 \Delta$ triple mutant were Cd sensitive (Fig 7A) suggesting that Snf1p phosphorylation is important for Cd tolerance. Indeed, the unphosphorylatable SNF1-T210A allele was unable to rescue growth of $s n f 1 \Delta$ in the presence of Cd (Fig 7B). To monitor Snf1p phosphorylation directly, we treated cells with cadmium (or low glucose as a control), prepared cell extracts and performed Western blot analysis using an anti-phospho-Snf1p antibody (Fig 7C). Basal Snf1p phosphorylation did not increase upon Cd-treatment whereas low glucose triggered strong Snf1p phosphorylation. No phosphorylation was detected in cells expressing the SNF1T210A allele. We also monitored phosphorylation of the transcriptional repressor Mig1p, which is targeted by Snf1p under low glucose conditions. Cd did not trigger Mig1p phosphorylation whilst Mig1p was strongly phosphorylated in low glucose conditions (Fig 7D). Together with the fact that mig1 $\Delta$ is not $\mathrm{Cd}$ sensitive (Fig 6A), these results indicate that $\mathrm{Snf} 1 \mathrm{p}$ action in Cd tolerance is differ-

B

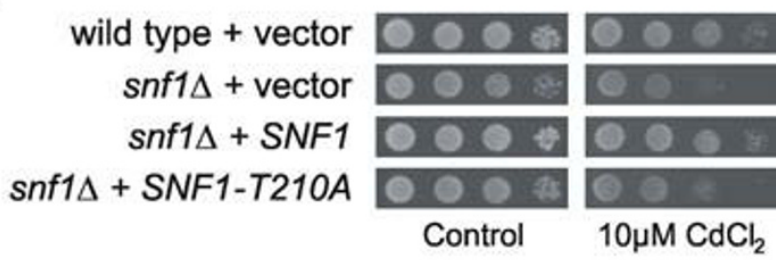

D

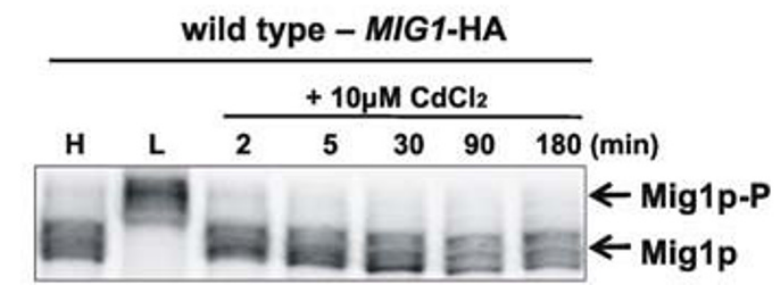

Figure 7

Snflp phosphorylation is required for Cd tolerance. (A) Cells lacking Snflp or proteins regulating its activity (Snf4p or the upstream kinases Saklp, Tos3p, Elm Ip) are cadmium sensitive. I0-fold serial dilutions of exponentially growing cells were spotted on YNB $+2 \%$ glucose agar plates containing cadmium and growth was scored after $2-3$ days at $30^{\circ} \mathrm{C}$. (B) Snfl P phosphorylation/kinase activity is required for cadmium tolerance.snfI $\Delta$ cells were transformed with a plasmid containing SNFI or the unphosphorylatable SNFI-T2IOA allele. Wild-type and snfI $\Delta$ cells were also transformed with the empty vector as a control. I0-fold serial dilutions of exponentially growing cells were spotted on selective medium with or without cadmium, and growth was scored after $2-3$ days at $30^{\circ} \mathrm{C}$. (C) Snflp phosphorylation is not induced by cadmium. Snflp phosphorylation was monitored with a phospho-specific-Snflp antibody whereas total Snflp was detected with anti-HA antibody. H: high glucose (2\%); L: low glucose (0.05\%). (D) Mig I p is not phosphorylated during cadmium exposure. Migl p was detected with anti-HA antibody and mobility was monitored in the presence of cadmium, low glucose (L: $0.05 \%)$ or high glucose (H: $2 \%)$. 
ent from that under low glucose conditions. Nevertheless, our data clearly shows that a low level of Snf1p kinase activity is necessary and sufficient to confer significant $\mathrm{Cd}$ tolerance to yeast cells. In line with this observation, low level of Snf1p kinase activity is sufficient to confer tolerance to other toxic agents like lithium and hydroxyurea $[79,80]$ although the mechanisms are not well understood. To conclude, high level of Snf1p kinase activity is required for growth in the absence of glucose while a low level of kinase activity is sufficient to confer tolerance to toxic agents when glucose is present.

\section{Conclusion}

This study has highlighted the importance of individual genes, pathways and cellular functions that protect yeast cells against arsenite and cadmium toxicity. We have pinpointed common as well as metal-specific defence functions and provided novel insight into As and Cd tolerance systems and toxicity targets. In particular, molecular evidence indicates that the cytoskeleton is a direct target of arsenite toxicity, and that the GIM complex is affected by arsenite in vivo. We also demonstrate that phosphorylation of the Snf1p kinase is necessary for Cd tolerance. These aspects of arsenite/cadmium toxicity and tolerance are novel and add to our understanding of metal action and tolerance acquisition mechanisms.

The fact that As and Cd has been included in some recent genome-wide phenotyping screens $[31,33,61,73,74]$ enabled us to assess the overlap between and the reliability of these studies. Although the overlap on the gene level was rather poor, the corresponding studies identified similar biological processes that are important for tolerance acquisition. The discrepancy at the gene level might be due to variations in experimental settings and/or due to that the screens are not saturated. Nevertheless, genomewide phenotypic screens provide biologically relevant insight into tolerance mechanisms, and phenotypic profiling under different conditions may enhance the reliability of the data.

What can we conclude about the mode of action of metals based on a genome-wide sensitivity screen? Even though phenotypic profiling pin-points core functions that confer metal tolerance, one cannot firmly conclude that those gene-products represent direct toxicity targets. In fact, many phenotypes could be a result of synthetic effects, e.g. the lacking gene product and the metal may affect parallel pathways/protective systems. A complementary approach may involve a search for genes that confer resistance upon overexpression since a gene that confers resistance when overexpressed and sensitivity when absent is more likely to be a direct target of the metal. However, it is clear that molecular and biochemical studies will ultimately be required to confirm whether a protein is indeed targeted by a metal or not. In this study, we provide both genomic and molecular evidence that the cytoskeleton and the GIM/prefoldin complex are targets of arsenite toxicity.

To conclude, this study has shed light on the genetic basis of arsenite and cadmium tolerance in S. cerevisiae. This catalogue of genes and protective functions will be instrumental for generating hypotheses about the role of individual factors for tolerance acquisition and for providing insights into the modes of metal action. Unveiling metal toxicity and tolerance mechanisms in yeast may prove of value for identifying similar mechanisms in higher eukaryotes.

\section{Methods}

Strains, plasmids, growth conditions and reagents

The complete set of viable yeast mutants in the haploid

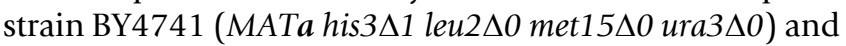
the homozygous diploid strain BY4743 (MATa/MAT his $3 \Delta 1 / h i s 3 \Delta 1$ leu $2 \Delta 0 /$ leu $2 \Delta 0$ ura3 $\Delta 0 /$ ura $3 \Delta 0$ LYS2/lys $2 \Delta 0$ met15 $\Delta 0 /$ MET15) from EUROSCARF [81] were screened for growth in the presence of various concentrations of cadmium chloride (Sigma) and sodium arsenite (Sigma). The strains were grown in the absence or presence of metal on YEPD ( $1 \%$ yeast extract, $1 \%$ peptone, $2 \%$ glucose) or YNB ( $0.67 \%$ yeast nitrogen base) medium supplemented with complete amino acid supplement mix (BIO101) and $2 \%$ glucose as carbon source. Tub1p-GFP and Tub3-GFP strains were obtained from Invitrogen, and the Snf1p pathway mutants (in W303-1A strain background) and the centromeric plasmids containing HA-tagged SNF1 and SNF1-T210A are described in [82]. The MIG1 gene was epitope tagged by chromosomal integration of a PCR amplified triple HA-tag using primers 5'-ACA AAC CCC CAT TTC TCA GTC GGA TTC ACA AGT TCA AGA ACT GGA AAC ATT ACC ACC CAT AAG AAG TTT ACC GTT GCC CTT CCC ACA CAT GGA CCG TAC GCT GCA GGT CGA $C$ and 5'-ATT ATT TAT TAT TTA TTA ATT ATT AAT TGT TAA TAT TAT TAA TTC TTG TCT ATT GTC TTT TGA TTT ATC TGC ACC GCC AAA AAC TTG TCA GCG TAT CAA TGC TCG TTA AAG TGT GTG GTT, and plasmid pYM22 [83].

\section{Screening and scoring for metal sensitivity}

An ordered array of $\sim 4700$ viable gene deletion mutants in the haploid BY4741 background was screened essentially as described in [84]. Strains were replica pinned onto YNB control plates and plates with cadmium chloride $(75,100$ and $150 \mu \mathrm{M})$ or sodium arsenite $(0.5,1.0$ and $1.5 \mathrm{mM})$ using a 96-floating pin replicator operated by a Biomek 2000 robot (Beckman). The strains were arrayed in quadruplet to create a dilution in a given square giving a total of 96 strains plated per agar plate (see Additional file 2). The plates were incubated at $30^{\circ} \mathrm{C}$ and photographed after 24,48 and 72 hours. The images were quantified in 
the image analysis software ImaGene v.6 (Biodiscovery) and spot area and intensity were extracted. The resulting data was then imported and analyzed in the statistical language $\mathrm{R}$ [85]. To remove technical artefacts and non-growing colonies the spots were filtered based on spot area and intensity. First, all control spots with an area less than 16 were removed. Then, spots with an area greater or equal to 16 but with the intensity within the spot less than the background intensity minus one standard deviation were: (1) removed if it was a control spot or (2) area set to 1 if it was a mutant. The logarithm of the fold-change between the mutant and control area was used as an estimate of the effect of metals on growth, where resistance and sensitivity is indicated by positive and negative values respectively. The logarithmic fold-changes were then normalized by subtracting an estimate plate effect, which was based on calculating the logarithmic fold-change between the median of the spots on the plates in question. Finally, the four replicates were added together using a trimmed mean value, where the highest and the lowest values were removed. Mutants with an average foldchange greater than 1.5 were selected for subsequent analysis.

The homozygous diploid BY4743 collection was screened essentially as described in [73]. In brief, cells were grown at $30^{\circ} \mathrm{C}$ in liquid YEPD medium with or without metal and cell density of each culture $\left(\mathrm{OD}_{600}\right)$ was measured after 24 and 48 hours. Sensitive mutants were re-screened to confirm slow growth in the presence of metal. Finally, the sensitive gene-sets from both screens (haploid and homozygous diploid) were pooled and used for further analysis.

\section{Data analyses}

To pin-point cellular functions that confer metal tolerance, we searched for functional categories (according to FunCat, Munich Information Center for Protein Sequences (MIPS)) [20] that were significantly enriched ( $p$-value $<0.005)$ in the sensitive gene-set as compared to the whole genome. Gene Ontology (GO) analysis was done using GO Term Finder [86], putative human homologues of As and Cd sensitive yeast genes were identified using the National Center for Biotechnology Information HomoloGene database [72], and affinity MS data for protein-protein interactions was obtained from [86]. Hierarchical clustering of metal and oxidative stress sensitive data was performed using Cluster 2.11 and visualized with Java TreeView 1.1.3 [87].

\section{Immunodetection, microscopy and staining methods}

Exponentially growing cells were either untreated or exposed to Cd, harvested and disrupted as described previously [82]. Proteins were separated by SDS-PAGE and analysed using anti-phospho-Snf1p antiserum (Open
Biosystems) or anti-HA antibody (Santa Cruz Biotechnology). IRDye goat $800 \mathrm{CW}$ anti-mouse or IRDye 680 antirabbit IgG were used as secondary antibodies. Filters were incubated with Odyssey blocking buffer (LI-COR Biosciences) and visualised using Odyssey IR scanner (LICOR Biosciences). To monitor Tub1p-GFP and Tub3pGFP, cells were grown in YEPD medium to mid-log phase, washed twice with phosphate-buffered saline (PBS) and the GFP signals were observed in living cells before and after exposure to arsenite. To visualize actin, cells were untreated or exposed to arsenite, and incubated with rhodamine-conjugated phalloidin (Invitrogen) as described in [88]. The GFP and rhodamine signals were observed using a Leica DM R fluorescence microscope.

\section{Abbreviations used}

ABC: ATP-binding cassette; MAP: mitogen-activated protein; ROS: reactive oxygen species; HOG: high osmolarity glycerol; As: arsenic; Cd: cadmium; Fe-S: iron-sulphur; SL: synthetic lethal; GFP: green fluorescent protein; PBS: phosphate-buffered saline.

\section{Authors' contributions}

MJT, GGP and MT conceived and designed the study; MT and GGP performed the genome-wide screens; TY performed phosphorylation experiments; MT, EK, GGP, MT and MJT analyzed the data; MJT, GP, EK, MT, IWD and ON participated in writing the paper; all authors approved the final manuscript.

\section{Additional material}

\section{Additional file 1}

Gene lists and data used for analysis. Excel sheet containing all gene lists and data used for analysis including As- and Cd-sensitive gene-sets, GO-annotations, FunCat analysis, and human homologues of yeast genes. Click here for file

[http://www.biomedcentral.com/content/supplementary/14712164-10-105-S1.xls]

\section{Additional file 2}

Representative 384-well plate from the primary metal screen. Figure showing a representative 384-well plate from the primary metal screen. Click here for file

[http://www.biomedcentral.com/content/supplementary/14712164-10-105-S2.pdf]

\section{Acknowledgements}

We thank Marc Sohrmann and Matthias Peter at the Swiss Federal Institute of Technology (ETH) in Zurich for providing access to the Biomek 2000 robot and for helping with the screen, Martin Schmidt (University of Pittsburgh School of Medicine) for plasmids, Stefan Hohmann (University of Gothenburg) for strains, and Marcus Krantz and Jonas Warringer (University of Gothenburg) for critical comments on this manuscript. We gratefully acknowledge financial support from the Swedish National Research School 
in Genomics and Bioinformatics to ON and MJT, the Swedish Research Council and University of Gothenburg Chemical Biology Platform to MJT, the foundation Knut och Alice Wallenberg Stiftelse in form of a travel grant to MT, and the Australian Research Council and Cancer Council of New South Wales to GGP and IWD.

\section{References}

I. Nordstrom DK: Public health. Worldwide occurrences of arsenic in ground water. Science 2002, 296(5576):2। 43-2। 45.

2. Goyer RA, Clarkson TW: Toxic effects of metals. In Casarett and Doull's Toxicology: the basic science of poisons Edited by: Klaassen CD. New York: McGraw-Hill; 200 I:8I I-867.

3. Stone R: Food safety. Arsenic and paddy rice: a neglected cancer risk? Science 2008, 32 I(5886): |84- |85.

4. Navarro Silvera SA, Rohan TE: Trace elements and cancer risk: a review of the epidemiologic evidence. Cancer Causes Control 2007, I 8(I):7-27.

5. International Agency for Research on Cancer [http:// www.iarc.fr]

6. Chen F, Shi $\mathrm{X}$ : Intracellular signal transduction of cells in response to carcinogenic metals. Crit Rev Oncol Hematol 2002, 42(I): $105-121$.

7. Ercal N, Gurer-Orhan H, Aykin-Burns N: Toxic metals and oxidative stress part I: mechanisms involved in metal-induced oxidative damage. Curr Top Med Chem 200I, I(6):529-539.

8. Tamás MJ, Martinoia E: Molecular biology of metal homeostasis and detoxification: from microbes to man. Heidelberg: Springer Verlag; 2005

9. Stohs SJ, Bagchi D: Oxidative mechanisms in the toxicity of metal ions. Free Radic Biol Med 1995, I 8(2):321-336.

10. Barrett MP, Burchmore RJ, Stich A, Lazzari JO, Frasch AC, Cazzulo JJ, Krishna S: The trypanosomiases. Lancet 2003, 362(9394): |469-|480.

I I. Fairlamb AH: Chemotherapy of human African trypanosomiasis: current and future prospects. Trends Parasitol 2003, I 9( I I):488-494.

12. Dilda PJ, Hogg PJ: Arsenical-based cancer drugs. Cancer Treat Rev 2007, 33(6):542-564.

13. Heffeter $P$, Jungwirth $U$, Jakupec $M$, Hartinger $C$, Galanski M, Elbling $L$, Micksche $M$, Keppler $B$, Berger $W$ : Resistance against novel anticancer metal compounds: Differences and similarities. Drug Resist Updat 2008, I I:I-16.

14. Krämer U: Phytoremediation: novel approaches to cleaning up polluted soils. Curr Opin Biotechnol 2005, I6(2): |33-|4|.

15. Tripathi RD, Srivastava S, Mishra S, Singh N, Tuli R, Gupta DK, Maathuis F): Arsenic hazards: strategies for tolerance and remediation by plants. Trends Biotechnol 2007, 25(4): I 58- I65.

16. Clemens S: Toxic metal accumulation, responses to exposure and mechanisms of tolerance in plants. Biochimie 2006, 88(I I): I707-1719.

17. Rosen BP: Families of arsenic transporters. Trends Microbiol 1999, 7:207-212

18. Tamás MJ, Wysocki R: Mechanisms involved in metalloid transport and tolerance acquisition. Curr Genet 200I, 40:2-12

19. Tamás MJ, Labarre J, Toledano MB, Wysocki R: Mechanisms of toxic metal tolerance in yeast. In Molecular biology of metal homeostasis and detoxification: from microbes to man Edited by: Tamás MJ, Martinoia E. Heidelberg: Springer Verlag; 2005:395-454.

20. Munich Information Center for Protein Sequences (MIPS) [http://mips.gsf.de]

21. Thorsen M, Lagniel G, Kristiansson E, Junot C, Nerman O, Labarre J, Tamás MJ: Quantitative transcriptome, proteome, and sulfur metabolite profiling of the Saccharomyces cerevisiae response to arsenite. Physiol Genomics 2007, 30(I):35-43.

22. Fauchon M, Lagniel G, Aude JC, Lombardia L, Soularue P, Petat C, Marguerie G, Sentenac A, Werner M, Labarre J: Sulfur sparing in the yeast proteome in response to sulfur demand. Mol Cell 2002, 9(4):713-723.

23. Vido K, Spector D, Lagniel G, Lopez S, Toledano MB, Labarre J: A proteome analysis of the cadmium response in Saccharomyces cerevisiae. J Biol Chem 200I, 276(I I):8469-8474.

24. Lafaye A, Junot C, Pereira Y, Lagniel G, Tabet JC, Ezan E, Labarre J: Combined Proteome and Metabolite-profiling Analyses Reveal Surprising Insights into Yeast Sulfur Metabolism. J Biol Chem 2005, 280(26):24723-24730.
25. Pompella A, Visvikis A, Paolicchi A, De Tata V, Casini AF: The changing faces of glutathione, a cellular protagonist. Biochem Pharmacol 2003, 66(8): |499-I503.

26. Grant CM: Role of the glutathione/glutaredoxin and thioredoxin systems in yeast growth and response to stress conditions. Mol Microbiol 200I, 39(3):533-54I.

27. Li ZS, Szczypka M, Lu YP, Thiele DJ, Rea PA: The yeast cadmium factor protein (YCFI) is a vacuolar glutathione $S$-conjugate pump. J Biol Chem 1996, 27 I(I I):6509-65I7.

28. Tommasini R, Evers R, Vogt E, Mornet C, Zaman GJ, Schinkel AH, Borst $P$, Martinoia $E:$ The human multidrug resistance-associated protein functionally complements the yeast cadmium resistance factor I. Proc Natl Acad Sci USA 1996, 93( I 3):6743-6748.

29. Ghosh M, Shen J, Rosen BP: Pathways of As(III) detoxification in Saccharomyces cerevisiae. Proc Natl Acad Sci USA 1999, 96(9):500I-5006.

30. Thomas D, Surdin-Kerjan Y: Metabolism of sulfur amino acids in Saccharomyces cerevisiae. Microbiol Mol Biol Rev 1997, 6 I (4):503-532.

31. Haugen AC, Kelley R, Collins JB, Tucker CJ, Deng C, Afshari CA, Brown JM, Ideker T, Van Houten B: Integrating phenotypic and expression profiles to map arsenic-response networks. Genome Biol 2004, 5(I 2):R95.

32. Momose $\mathrm{Y}$, Iwahashi $\mathrm{H}$ : Bioassay of cadmium using a DNA microarray: genome-wide expression patterns of Saccharomyces cerevisiae response to cadmium. Environ Toxicol Chem 200I, 20( I 0):2353-2360.

33. Jin YH, Dunlap PE, McBride SJ, Al-Refai H, Bushel PR, Freedman JH: Global transcriptome and deletome profiles of yeast exposed to transition metals. PLoS Genet 2008, 4(4):e I000053.

34. Gavin AC, Aloy P, Grandi P, Krause R, Boesche M, Marzioch M, Rau $C$, Jensen LJ, Bastuck S, Dumpelfeld B, Edelmann A, Heurtier MA, Hoffman V, Hoefert C, Klein K, Hudak M, Michon AM, Schelder M, Schirle M, Remor M, Rudi T, Hooper S, Bauer A, Baumeester T, Casari G, Drewes G, Neubauer G, Rick JM, Kuster B, Bork P, Russell RB, Superti-Furga G: Proteome survey reveals modularity of the yeast cell machinery. Nature 2006, 440(7084):63 I-636.

35. Leroy C, Cormier L, Kuras L: Independent recruitment of mediator and SAGA by the activator Met4. Mol Cell Biol 2006, 26(8):3 I 49-3163.

36. Thorsen M, Di Y, Tangemo C, Morillas M, Ahmadpour D, Does C Van der, Wagner A, Johansson E, Boman J, Posas F, Wysocki R, Tamás MJ: The MAPK Hoglp modulates FpsIp-dependent arsenite uptake and tolerance in yeast. Mol Biol Cell 2006, I 7( I 0):4400-44 I0.

37. Wysocki R, Chéry CC, Wawrzycka D, Van Hulle M, Cornelis R, Thevelein JM, Tamás MJ: The glycerol channel Fps I p mediates the uptake of arsenite and antimonite in Saccharomyces cerevisiae. Mol Microbiol 200I, 40:1391-I40I.

38. Migdal I, llina Y, Tamás MJ, Wysocki R: Mitogen-activated protein kinase Hog I mediates adaptation to $G_{\text {, scheckpoint arrest }}$ during arsenite and hyperosmotic stress. Eukaryot Cell 2008, 7(8): |309-13|7.

39. Bilsland E, Molin C, Swaminathan S, Ramne A, Sunnerhagen P: Rck I and Rck2 MAPKAP kinases and the HOG pathway are required for oxidative stress resistance. Mol Microbiol 2004, 53(6): $1743-1756$

40. Bermejo C, Rodriguez E, Garcia R, Rodriguez-Pena JM, Rodriguez de la Concepcion ML, Rivas C, Arias P, Nombela C, Posas F, Arroyo J: The Sequential Activation of the Yeast HOG and SLT2 Pathways Is Required for Cell Survival to Cell Wall Stress. Mol Biol Cell 2008, I 9(3): I I I3- I I24.

41. Dudley AM, Janse DM, Tanay A, Shamir R, Church GM: A global view of pleiotropy and phenotypically derived gene function in yeast. Mol Syst Biol 2005, I:. 20050001

42. Hillenmeyer ME, Fung E, Wildenhain J, Pierce SE, Hoon S, Lee W Proctor M, St Onge RP, Tyers M, Koller D, Altman RB, Davis RW, Nislow C, Giaever G: The chemical genomic portrait of yeast: uncovering a phenotype for all genes. Science 2008, 320(5874):362-365.

43. Taylor BF, McNeely SC, Miller HL, States JC: Arsenite-induced mitotic death involves stress response and is independent of tubulin polymerization. Toxicol Appl Pharmacol 2008, 230:235-246. 
44. Ralph SJ: Arsenic-based antineoplastic drugs and their mechanisms of action. Met Based Drugs 2008, 2008:260I46.

45. Vujcic M, Shroff M, Singh KK: Genetic determinants of mitochondrial response to arsenic in yeast Saccharomyces cerevisiae. Cancer Res 2007, 67(20):9740-9749.

46. Liu SX, Davidson MM, Tang X, Walker WF, Athar M, Ivanov V, Hei TK: Mitochondrial damage mediates genotoxicity of arsenic in mammalian cells. Cancer Res 2005, 65(8):3236-3242.

47. Garcia JJ, Martinez-Ballarin E, Millan-Plano S, Allue JL, Albendea C, Fuentes L, Escanero JF: Effects of trace elements on membrane fluidity. J Trace Elem Med Biol 2005, I 9(1):19-22.

48. Suwalsky M, Rivera C, Sotomayor CP, Jemiola-Rzeminska M, Strzalka $\mathrm{K}$ : Monomethylarsonate (MMAv) exerts stronger effects than arsenate on the structure and thermotropic properties of phospholipids bilayers. Biophys Chem 2008, I 32(I): I-8.

49. Loukin SH, Kung C, Saimi Y: Lipid perturbations sensitize osmotic down-shock activated $\mathrm{Ca}^{+}$influx, a yeast "deletome" analysis. Faseb J 2007, 21(8): |8|3-|820.

50. Toh TH, Kayingo G, Merwe MJ van der, Kilian SG, Hallsworth JE, Hohmann S, Prior BA: Implications of FPSI deletion and membrane ergosterol content for glycerol efflux from Saccharomyces cerevisiae. FEMS Yeast Res 200I, I(3):205-2II.

5I. Li W, Chou IN: Effects of sodium arsenite on the cytoskeleton and cellular glutathione levels in cultured cells. Toxicol Appl Pharmacol 1992, I I 4(I): I32-139.

52. Qian Y, Liu KJ, Chen Y, Flynn DC, Castranova V, Shi X: Cdc42 reg ulates arsenic-induced NADPH oxidase activation and cell migration through actin filament reorganization. J Biol Chem 2005, 280(5):3875-3884.

53. Menzel DB, Hamadeh HK, Lee E, Meacher DM, Said V, Rasmussen RE, Greene $\mathrm{H}$, Roth $\mathrm{RN}$ : Arsenic binding proteins from human lymphoblastoid cells. Toxicol Lett 1999, 105(2):89-101.

54. Hoffman RD, Lane MD: lodophenylarsine oxide and arsenical affinity chromatography: new probes for dithiol proteins. Application to tubulins and to components of the insulin receptor-glucose transporter signal transduction pathway. Biol Chem 1992, 267(20): |4005- |40||.

55. Bobrowicz P, Wysocki R, Owsianik G, Goffeau A, Ulaszewski S: Isolation of three contiguous genes, ACRI, ACR2 and ACR3, involved in resistance to arsenic compounds in the yeast Saccharomyces cerevisiae. Yeast 1997, 13(9):819-828.

56. Wysocki R, Bobrowicz P, Ulaszewski S: The Saccharomyces cerevisiae $A C R 3$ gene encodes a putative membrane protein involved in arsenite transport. J Biol Chem 1997 272(48):3006I-30066.

57. Mukhopadhyay R, Rosen BP: Saccharomyces cerevisiae ACR2 gene encodes an arsenate reductase. FEMS Microbiol Lett 1998 , 168(I): $127-136$

58. Wysocki R, Fortier PK, Maciaszczyk E, Thorsen M, Leduc A, Odhagen A, Owsianik G, Ulaszewski S, Ramotar D, Tamás MJ: Transcriptional activation of metalloid tolerance genes in Saccharomyces cerevisiae requires the AP-I-like proteins Yaplp and Yap8p. Mol Biol Cell 2004, I 5(5):2049-2060.

59. Di Y, Tamás MJ: Regulation of the arsenic-responsive transcription factor Yap8p involves the ubiquitin-proteasome pathway. I Cell Sci 2007, I 20(Pt 2):256-264.

60. Ilina Y, Sloma E, Maciaszczyk-Dziubinska E, Novotny M, Thorsen M, Wysocki R, Tamás MJ: Characterization of the DNA binding motif of the arsenic-responsive transcription factor Yap8p. Biochem J 2008, 4I 5(3):467-475.

61. Ruotolo R, Marchini G, Ottonello S: Membrane transporters and protein traffic networks differentially affecting metal tolerance: a genomic phenotyping study in yeast. Genome Biol 2008 9(4):R67.

62. Yoshihara T, Hodoshima H, Miyano Y, Shoji K, Shimada H, Goto F: Cadmium inducible $\mathrm{Fe}$ deficiency responses observed from macro and molecular views in tobacco plants. Plant Cell Rep 2006, 25(4):365-373.

63. Philpott CC, Protchenko O: Response to iron deprivation in Saccharomyces cerevisiae. Eukaryot Cell 2008, 7(I):20-27.

64. Shakoury-Elizeh M, Tiedeman J, Rashford J, Ferea T, Demeter J, Garcia E, Rolfes R, Brown PO, Botstein D, Philpott CC: Transcriptiona remodeling in response to iron deprivation in Saccharomyces cerevisiae. Mol Biol Cell 2004, I 5(3): I233-1243.

65. Chen OS, Crisp RJ, Valachovic M, Bard M, Winge DR, Kaplan J: Transcription of the yeast iron regulon does not respond directly to iron but rather to iron-sulfur cluster biosynthesis. I Biol Chem 2004, 279(28):295I3-295I8.

66. Hedbacker K, Carlson M: SNFI/AMPK pathways in yeast. Front Biosci 2008, I 3:2408-2420.

67. Blumenthal SS, Lewand DL, Buday MA, Kleinman JG, Krezoski SK, Petering DH: Cadmium inhibits glucose uptake in primary cultures of mouse cortical tubule cells. Am J Physiol I 990, 258(6 Pt 2):FI625-1633.

68. Liu SX, Athar M, Lippai I, Waldren C, Hei TK: Induction of oxyradicals by arsenic: implication for mechanism of genotoxicity. Proc Natl Acad Sci USA 200I, 98(4): I643-I648.

69. Brennan RJ, Schiestl RH: Cadmium is an inducer of oxidative stress in yeast. Mutat Res 1996, 356(2): I7I-I78.

70. Thorpe GW, Fong CS, Alic N, Higgins VJ, Dawes IW: Cells have distinct mechanisms to maintain protection against different reactive oxygen species: oxidative-stress-response genes. Proc Natl Acad Sci USA 2004, I 0 I ( I 7):6564-6569.

7I. Birrell GW, Brown JA, Wu HI, Giaever G, Chu AM, Davis RW Brown JM: Transcriptional response of Saccharomyces cerevisiae to DNA-damaging agents does not identify the genes that protect against these agents. Proc Natl Acad Sci USA 2002, 99(13):8778-8783

72. National Center for Biotechnology Information (NCBI) [http://www.ncbi.nlm.nih.gov/]

73. Dilda PJ, Perrone GG, Philp A, Lock RB, Dawes IW, Hogg PJ: Insight into the selectivity of arsenic trioxide for acute promyelocytic leukemia cells by characterizing Saccharomyces cerevisiae deletion strains that are sensitive or resistant to the metalloid. Int J Biochem Cell Biol 2008, 40(5): 1016-1029.

74. Serero A, Lopes J, Nicolas A, Boiteux S: Yeast genes involved in cadmium tolerance: Identification of DNA replication as a target of cadmium toxicity. DNA Repair (Amst) 2008, 7:1262-1275

75. Geissler S, Siegers K, Schiebel E: A novel protein complex promoting formation of functional alpha- and gamma-tubulin. Embo J 1998, I7(4):952-966

76. Stirling PC, Cuellar J, Alfaro GA, El Khadali F, Beh CT, Valpuesta JM, Melki R, Leroux MR: PhLP3 modulates CCT-mediated actin and tubulin folding via ternary complexes with substrates. Biol Chem 2006, 28 I (I I):70I2-702I.

77. Vainberg IE, Lewis SA, Rommelaere H, Ampe C, Vandekerckhove J, Klein HL, Cowan NJ: Prefoldin, a chaperone that delivers unfolded proteins to cytosolic chaperonin. Cell 1998, 93(5):863-873.

78. Yuzyuk T, Foehr M, Amberg DC: The MEK kinase Ssk2p promotes actin cytoskeleton recovery after osmotic stress. Mol Biol Cell 2002, I3(8):2869-2880.

79. Portillo F, Mulet JM, Serrano R: A role for the non-phosphorylated form of yeast Snfl: tolerance to toxic cations and activation of potassium transport. FEBS Lett 2005, 579(2):5I2-5I6.

80. Dubacq C, Chevalier A, Mann C: The protein kinase SnfI is required for tolerance to the ribonucleotide reductase inhibitor hydroxyurea. Mol Cell Biol 2004, 24(6):2560-2572.

81. EUROSCARF [http://web.uni-frankfurt.de/fb/5/mikro/euroscarf/]

82. Ye T, Elbing K, Hohmann S: The pathway by which the yeast protein kinase Snfl p controls acquisition of sodium tolerance is different from that mediating glucose regulation. Microbiology 2008, I54(Pt 9):28|4-2826

83. J Janke C, Magiera MM, Rathfelder N, Taxis C, Reber S, Maekawa H, Moreno-Borchart A, Doenges G, Schwob E, Schiebel E, Knop M: A versatile toolbox for PCR-based tagging of yeast genes: new fluorescent proteins, more markers and promoter substitution cassettes. Yeast 2004, 2 I ( I I ):947-962.

84. Aouida M, Page N, Leduc A, Peter M, Ramotar D: A genome-wide screen in Saccharomyces cerevisiae reveals altered transport as a mechanism of resistance to the anticancer drug bleomycin. Cancer Res 2004, 64(3): I 102-I 109.

85. R Development Core Team: R: A language and environment for statistical computing. [http://www.R-project.org].

86. Saccharomyces Genome Database (SGD) [http://www.yeastge nome.org]

87. Eisen MB, Spellman PT, Brown PO, Botstein D: Cluster analysis and display of genome-wide expression patterns. Proc Natl Acad Sci USA 1998, 95(25): 14863-14868. 
88. Rose MD, Winston F, Hieter P: Methods in Yeast Genetics. A Laboratory Course Manual. Cold Spring Harbor, NY: Cold Spring Harbor Laboratory Press; 1990.

Publish with Bio Med Central and every scientist can read your work free of charge

"BioMed Central will be the most significant development for disseminating the results of biomedical research in our lifetime. " Sir Paul Nurse, Cancer Research UK

Your research papers will be:

- available free of charge to the entire biomedical community

- peer reviewed and published immediately upon acceptance

- cited in PubMed and archived on PubMed Central

- yours - you keep the copyright

Submit your manuscript here:

http://www.biomedcentral.com/info/publishing_adv.asp
BioMedcentral 